\title{
Las traducciones del Decameron de Boccaccio en España (1800-1940)
}

\author{
Cesáreo Calvo Rigual \\ Universitat de València \\ Cesareo.Calvo@uv.es
}

\section{Abstract}

Se pasa revista a todas las traducciones del Decameron (totales, parciales, adaptaciones) hechas en España entre 1800 y 1940. Las numerosas antologías estudiadas priorizan las novelle de mayor carga erótica o anticlerical, aunque a menudo ésta queda diluida por la censura o la autocensura. El balance es bastante pobre: el Decameron fue publicado en contadas ocasiones por un editor de prestigio y por un traductor capaz; la mayoría de las traducciones se hicieron desde el francés, produciéndose además numerosos plagios entre ellas; el número real de traducciones, por tanto, resulta ciertamente reducido (sólo una de las tres completas es traducción directa del italiano). La lengua empleada en las traducciones es en conjunto pobre. La obra de Boccaccio no pudo llegar de forma fiel a los lectores españoles en este periodo: habrá que esperar hasta la segunda mitad del siglo XX.

Palabras clave: Boccaccio, Decameron, traducción, España.

\section{Abstract}

This is a review of every translation of the Decameron (total, partial, adaptations) undertaken in Spain between 1800 and 1940. Many of the anthologies reviewed give priority to the novelle with greater erotic or anticlerical content, although this is often toned down by censure or self-censure. The result is rather poor: the Decameron has been published on very few occasions by a renowned editor or a skilled translator. Most of the translations are from the French, and many of these plagiarise each other. The real number of translations is therefore quite low (only one of the three complete translations is directly from the Italian). The language used in the translations is generally poor. Boccaccio's work was not faithfully translated during this period. Spanish readers must wait until the second half of the $20^{\text {th }}$ century.

Key words: Boccaccio, Decameron, translation, Spain. 
La obra cumbre de Boccaccio en lengua vulgar se difundió con relativa rapidez en tierras hispanas. En 1429, en Sant Cugat del Vallés, daba fin a la versión catalana un anónimo traductor. ${ }^{1}$ Por aquellas mismas fechas, o quizás algún decenio más tarde, debió de llevarse a cabo la primera traducción castellana, también anónima, de la que se conserva un códice formado por 50 novelle, ${ }^{2}$ que, junto con otras cincuenta, fue publicada en 1496 con el título de Las Cien novelas. ${ }^{3}$ Esta edición, impresa otras cuatro veces hasta 1550 , sería durante el siglo XVI el único texto accesible en España para quien desconociese el italiano. Su inclusión en el Índice de Valdés (1559) condenó la obra al ostracismo, si bien siguió suministrando argumentos a los escritores durante todo el siglo XVII. En el XVIII se apaga casi definitivamente su estrella no sólo por razones de censura, sino también de gusto. ${ }^{4}$

1. Se trata de una bella traducción íntegra de la que se conserva un manuscrito único en la Biblioteca de Catalunya (Ms. 1716). No fue editada hasta 1910 por Massó (Giovanni BocCACCIO, Decameron de Johan Boccaci, traducció catalana publicada, segons l'únic manuscrit conegut, (1429), per J. Massó Torrents. Nueva York: The Hispanic Society of America («Biblioteca Hispánica»), 1910), aunque de forma escasamente fiable, como señala Colón (Germà COLÓN, "Un aspecte estilístic de la traducció catalana medieval del "Decameron»", en La llengua catalana en els seus textos. Barcelona: Curial Edicions Catalanes, 1978, p. 235253). Los dos primeros volúmenes aparecerían poco más tarde en la colección «Els nostres clàssics» de Barcino: Giovanni BocCACCIO, Decameró, versió catalana de 1429; introducció de Carles Riba. Barcelona: Barcino, 1926-1928. Sobre esta traducción véanse: Lola BADIA, "Sobre la traducciò catalana del Decameron de 1429", Boletín de la Real Academia de Buenas Letras de Barcelona, n. 35, 1973-74, p. 60-101; Isidre BONSOMS I SISCART, "Introducción a la lectura de unos fragmentos de las traducciones catalanas de la Fiammetta y del Decamerone de Boccaccio, ambas anónimas y hechas en el siglo XV", Boletín de la Real Academia de Buenas Letras de Barcelona, n. 4 y 5, 1907-08, 1909-10, p. 382-99, 387-88; Caroline B. BOURLAND, "Boccaccio and the Decameron in Castilian and Catalan Literature, New York", Revue Hispanique, n. 12, 1905, p. 1-232; Mario CASELLA, «La versione catalana del Decamerone», Archivum Romanicum, n. 9, 1925, p. 383-420 (luego en Saggi di letteratura provenzale e catalana, Bari: Adriatica, 1966); Barbara RENESTO, «Note sulla traduzione catalana del Decameron del 1429", Cuadernos de Filología Italiana, n. extraordinario, 2001, p. 295-314; Martí de RIQUER, «Boccaccio nella letteratura catalana medievale», en Boccaccio nelle culture e letterature nazionali, Florencia: Olschki, 1974, p. 107-26. Una nueva transcripción y edición se encuentra en la tesis doctoral de C. Cabré i Moné, Traducció catalana del «Decameron» (1429), edició critica (Barcelona: Universitat de Barcelona, 1986).

2. Conservado en la Biblioteca del Monasterio de El Escorial, signatura J.II.21.

3. Es aún objeto de debate crítico la relación entre el códice y el incunable, así como la procedencia de una novella apócrifa en este último. Sobre esta traducción véanse: Carlos ALVAR, «Boccaccio en Castilla: entre recepción y traducción», Cuadernos de Filología Italiana, n. 8, 2001, p. 333-350; Joaquín ARCE FERNÁNDEZ, «Boccaccio nella letteratura castigliana: panorama generale e rassegna bibliografico-critica», en Boccaccio nelle culture e letterature nazionali, Florencia: Olschki, 1974, p. 63-105; ID., «Seis cuestiones sobre el tema Boccaccio en España", Filología Moderna, n. 54, 1975, p. 473-89; José BlanCo JimÉnEZ, Le opere di Giovanni Boccaccio in Spagna nel '400 e '500: una prima valutazione bibliografica, Florencia: Tip. Baccini, 1977; ID., Presencia de Boccaccio en España (con algunas correcciones), Santiago de Chile, 1978; Caroline B. Bourland, op. cit.; Arturo Farinell, "Boccaccio in Spagna», en ID., Italia e Spagna, Torino: Fratelli Bocca, 1929, p. 91-97.

4. Véanse los dos trabajos de Joaquín Arce citados para la literatura en lengua castellana; para la catalana véase el también citado de Martín de Riquer. 
Debemos esperar hasta la centuria siguiente para encontrar en España alguna huella editorial de la presencia en España del autor, que se hará más conspicua a partir de los años Setenta. Sin embargo, como trataremos de aclarar en este trabajo, la difusión del Decameron adquirirá un nivel digno en nuestro país sólo en el último tercio del siglo XX, más allá del límite cronológico que nos hemos marcado. Las primeras traducciones modernas del Decameron consistieron, de hecho, en adulteraciones del texto original a partir de versiones francesas, en antologías de trazo grueso o corte obsceno, y en pocas versiones directas estilísticamente adocenadas.

Las dos traducciones cuatrocentistas españolas del Decameron han sido estudiadas por numerosos especialistas, aunque falta aún una edición crítica fiable de ambos textos. Casi inexistentes son, en cambio, los estudios sobre las traducciones modernas del período que aquí nos ocupa, ${ }^{5}$ y ello pese al influjo que Boccaccio ha seguido ejerciendo sobre la literatura universal, y al alto lugar que le corresponde como una de las «tres coronas» de la literatura italiana. Aquí intentaremos ayudar a colmar esta laguna trazando un panorama de las versiones anteriores a 1940, fruto de búsquedas azarosas en bibliotecas, hemerotecas o librerías anticuarias, con el fin de realizar un primer balance crítico (se añadirá al final el catálogo bibliográfico completo). ${ }^{6}$

\section{Novelle traducidas}

Cabe ante todo distinguir dos grupos de traducciones del Decameron: las completas y las parciales. Entre las primeras se cuentan sólo tres: la anónima de 1876 (luego plagiada y reimpresa en repetidas ocasiones), la de Luis Obiols [1904] y la de Germán Gómez de la Mata [1928]. La primera, si se exceptúa el proemio y la conclusión, carece del marco narrativo, elemento de gran importancia estructural en el conjunto de la obra. La mayoría de las restantes se limita a una breve selección o incluso a una sola novella. Se trata, además, de un grupo extraordinariamente heterogéneo que trataremos de ordenar conforme a la siguiente tipología:

a) Adaptaciones en verso. Son características de la primera mitad del siglo XIX $\mathrm{y}$ forman parte de recopilaciones más amplias que incluyen obras del pro-

5. Con pocas excepciones: María Hernández EstebAN, «Dos antologías madrileñas del «Decameron" de la época republicana entre la libertad y la censura», Cuadernos de Filología Italiana, n. 10, 2003, p. 157-169; Cesáreo CALVO RiguAL, «Boccaccio in Spagna: traduzioni, ritraduzioni e plagi di una novella (III, 1)», Fortuna e traduzioni del Decameron in Europa, XXXV Convegno sui problemi della traduzione, Padova: Il Poligrafo, en prensa; y en parte J. ARCE («Boccaccio nella letteratura castigliana», cit.).

6. Al final se encontrará una lista completa de las traducciones y sus ediciones. A lo largo de este trabajo nos referiremos a ellas con el número entre corchetes que precede a cada una de ellas en dicha lista y que normalmente coincide con el año de publicación de la primera edición. Si en un mismo año hubiera más de una traducción se distinguirán entre sí mediante una letra colocada tras la fecha. 
pio traductor-adaptador o de otros autores. Se trata de adaptaciones extremadamente libres, no sólo por la tiranía del verso, sino porque se añade y se quita todo aquello que se juzga oportuno, sin mayores contemplaciones. La de Torres [1818] supone la reaparición de Boccaccio en las prensas españolas tras más de tres siglos y medio, y lo hace en su vertiente más procaz (las novelle VII 3, VIII 2, VII 6 y VII 7), lo que sin duda, unido a su éxito (cuatro reediciones hasta 1828), contribuiría a consolidar el estereopito de un Boccaccio libertino, constante en casi todas las antologías estudiadas. La otra adaptación en verso - [1849]— es una recopilación de poemillas eróticos publicada probablemente en España con pie de imprenta falso para evitar la censura. ${ }^{7}$ Mientras que en la obra de Torres se identifican claramente los cuentos de Boccaccio versificados, en la del autodenominado «Padre Alegre» sólo aparece el nombre de Boccaccio en la portada, por lo que la identificación de la única novella presente es mucho más ardua.

b) Adaptaciones teatrales (zarzuelas). Más que de traducciones se trata de obras autónomas que toman ciertos episodios boccacianos para desarrollarlos libremente. Corresponden al final del siglo XIX y principios del XX, y parecen ser continuación del uso que los dramaturgos del XVII hicieron del Decameron, explotado como rico depósito de argumentos. La elección de las novelle es bastante uniforme: en todos los casos predomina el equívoco o la anécdota, generalmente de tipo erótico (VII 7, I 4 o IX 2, III 2, VII 4, III 3), es decir, situaciones y tramas particularmente idóneas para el juego escénico de la comedia.

c) Traducciones (en prosa) de una sola «novella». Son tres: [1865], [1875] y [1884]. La primera aparece en un pequeño volumen misceláneo que aparentemente pretende acercar autores clásicos españoles y extranjeros. ${ }^{8}$ La segunda, debida a Milà i Fontanals, se encuadra en la iniciativa de Giovanni Papanti de celebrar el centenario de la muerte de Boccaccio recopilando versiones de la novella I 9, la más corta del Decameron, en diferentes lenguas y dialectos. La tercera forma parte de una de las numerosísimas publicaciones periódicas de carácter popular de la época (El cuento semanal, Novelas y Cuentos, etc. ), que sacaban al mercado semanalmente cuentos o novelle a precio muy reducido en ediciones

7. Sólo se ha localizado un ejemplar (Biblioteca de la Real Academia Española). Este hecho (la rareza de los ejemplares) va a ser una constante en este trabajo, como veremos, lo que demuestra que, junto a una voluntad de ciertos editores por promover la obra de Boccaccio - de forma discutible, si queremos— por la otra encontramos a implacables censores que la persiguieron y casi consiguieron borrar su memoria.

8. Resultan instructivos los datos contenidos en su portada: «Obras clásicas y estrangeras [...] ¡Cuatro cuartos!!! |¿Quereis popularizar una literatura? Hacerla buena, dice el arte. Abaratarla, responde la industria. Regalo a los suscritores: toda nuestra variadisima coleccion: partiendo de Cervantes, el primer ingenio del mundo; Boccacio, el padre del chiste; el cáustico Quevedo [...] Sección picaresca: obras clasicas españolas y estrangeras de Boccacio.El marido engañado.-Cervantes.-La tia fingida.-Quevedo.-Casa de locos». 
de gran tirada y en impresiones de muy escasa calidad. La novella elegida en este caso es la I 4, donde el tema erótico se mezcla con la crítica a los eclesiásticos. ${ }^{?}$

d) Traducciones (en prosa) de dos o más novelle. Este es quizá el grupo más interesante, pues el antólogo o el traductor han tenido que proceder a una selección representativa. Son las de Aranda [1888b], Larrañaga [1920], un anónimo [1924], Barriobero [1932] y otro anónimo [1933]. Se trata de antologías muy diferentes cuyas características valdrá la pena analizar por separado. Todas ellas tienen, sin embargo, tres cosas en común: la eliminación del marco narrativo, la ordenación más bien aleatoria de las novelle elegidas respecto al orden original y la invención de títulos facticios:

- Aranda [1888b]: su antología se compone de 17 novelle. La elección del traductor recae claramente sobre las novelle en las que se exalta el ingenio o la burla ingeniosa (jornadas II, III y VIII), aunque no faltan otras en las que predomina el hecho afortunado (jornada V). Fuera de estos temas quedan IV 4 (notablemente trágica) o la famosa X 10 sobre la historia de Griselda. Está ausente, por tanto, la crítica a los clérigos, mientras que la presencia del sexo es más bien discreta (con alguna excepción: III 2, III 3, aunque aquí la elección parece haberse basado en el ingenio que se despliega para obtener el goce erótico). Que Aranda se aleja del criterio dominante en las otras antologías lo demuestra el simple hecho de que en la suya aparecen 13 novelle que sólo él ha tenido en cuenta: III 9, V 1, 2, 3, 9, VIII 3, 5, 6, 7, 9, 10, X 6,10 .

- Larrañaga [1920]: el único volumen que conservamos de lo que tal vez fue un proyecto de traducción completa a juzgar por el título (Cien cuentos de Boccaccio), consta de 25 novelle, escogidas entre casi todas las jornadas (faltan solo la III y la V), sin un criterio discernible. Tampoco el orden en el que se disponen da pistas sobre el criterio de elección, por lo que cabe pensar más bien en una serie abierta de tomitos separados, como sugieren las portadillas independientes de cada cuento.

- Anónima de [1924]: comprende 16 novelle. La orientación de base viene dada por el título mismo: Los cuentos más alegres y mejores del Decamerón. Si bien es cierto que se incluyen algunos de los considerados tradicionalmente «mejores», los hilos argumentales escogidos por el anónimo antólogo son, como de costumbre, el erotismo, el anticlericalismo y el ensalzamiento del ingenio sobre todo en situaciones cómicas.

- Barriobero [1932]: el título de esta recopilación de 15 novelle no podría ser más explícito acerca de las intenciones del traductor: Frailes, curas

9. Aunque, como veremos, todo ello resulta notablemente recortado quizá por la autocensura del traductor. 
y monjas de Boccaccio: antología de cuentos eróticos. En efecto, en todos los cuentos los protagonistas son religiosos de uno u otro sexo, retratados como grandes quebrantadores del sexto mandamiento o embaucadores del prójimo. Es, pues, una rotunda sátira anticlerical aliñada con toques picantes, que no puede sorprender en quien fue diputado republicano y acérrimo defensor del principio de la aconfesionalidad del Estado durante el proceso de aprobación de la Constitución española de $1931 .{ }^{10}$

- Anónima de [1933]: la última antología incluye 12 novelle, todas ellas tomadas de las cuatro primeras jornadas (sobre todo de II, III y IV). Mientras que los seis primeros cuentos responden a cierto orden, los seis restantes se presentan en caótica sucesión con respecto al original. La mayoría se centra en el tema del elogio del ingenio para lograr un fin o salir airoso de una situación peligrosa, aunque hay también tres relatos trágicos (IV 1, IV 8, IV 4) y alguno con una cierta osadía en el terreno sexual (III 2, III 3).

Si tomamos en su conjunto las antologías y las traducciones o adaptaciones podemos observar que de la selección quedan sistemáticamente excluidos los siguientes cuentos: I 1, 5, 7, 8; II 1, 4, 6, 8; III 5; IV 3, 6; V 4, 5, 6, 7, 8; VI 1, 2, 3, 4, 5, 7, 9; VII 1; IX 1, 4, 7, 8, 9; X 3, 5, 7, 8, 9. Es significativo que de algunas jornadas se hayan traducido todas o casi todas las novelle: III (chi una cosa a lungo desiderata ottiene o ritrova), IV (amori infelici), VII (beffe fatte per amore o per paura dalle donne ai loro amanti) y VIII (qualunque tipo di beffa), mientras que faltan la mitad o más de las jornadas V (felicità raggiunta dagli amanti dopo avventure e casi straordinari), VI (motti spiritosi o pronti che evitano danno o scorno), IX (tema libero) y X (chi, con cortesia e magnanimità ha avuto avventure d'amore o di altro genere). En suma, parecen haber gozado de menor aceptación las novelle que se encuentran en jornadas con mayor intención ejemplarizante (como la $\mathrm{V}$ o la $\mathrm{X}$ ) o en las que se ensalza la habilidad verbal (jornada VI). Teniendo en cuenta que en todos los casos el marco narrativo ha sido ignorado, observaciones referentes a las preferencias por una $\mathrm{u}$ otra Jornada no resultan del todo pertinentes, pues otras consideraciones, como lo erótico o la crítica anticlerical, parecen haber tenido un peso mayor a la hora de elegir los textos, tal como demuestra la lista de las novelle que han sido traducidas un mayor número de veces:

- Cinco veces: I 4.

- Cuatro veces: III 1, III 2, VII 7, VIII 2.

— Tres veces: III 3, IV 8, IX 2.

10. Él mismo costeó la edición del discurso pronunciado a tal fin en la Cámara: Palabras de un incrédulo. El problema religioso en el Parlamento y en la calle, Madrid: Galo Sáez, 1931. 

ciones:

En el cuadro siguiente pueden apreciarse de forma sintética las propor-

\begin{tabular}{cccl}
\hline Jornada & $\begin{array}{l}\text { Novelle } \\
\text { traducidas }\end{array}$ & $\begin{array}{l}\text { Número de } \\
\text { traducciones }\end{array}$ & Tema \\
\hline I & 6 & 13 & Tema libre \\
\hline II & 6 & 9 & Aventuras con final feliz \\
\hline III & 9 & 17 & $\begin{array}{l}\text { Hallazgo u obtención de algo largamente per- } \\
\text { seguido }\end{array}$ \\
\hline IV & 8 & 12 & Amores infelices \\
\hline V & 5 & 5 & $\begin{array}{l}\text { Felicidad conseguida por los amantes tras } \\
\text { aventuras y casos extraordinarios }\end{array}$ \\
\hline VI & 3 & 3 & Agudezas que evitan un daño o deshonor \\
\hline VII & 9 & 14 & $\begin{array}{l}\text { Burlas de las mujeres hechas por amor o por } \\
\text { temor a sus amantes }\end{array}$ \\
\hline VIII & 10 & 14 & Cualquier tipo de burla \\
\hline IX & 5 & 8 & Tema libre \\
\hline X & 5 & 6 & $\begin{array}{l}\text { Aventuras amorosas o de otro tipo conduci- } \\
\text { das con cortesía y magnanimidad }\end{array}$ \\
\hline & & &
\end{tabular}

\section{Los traductores}

Las traductores del Decameron en este período no han sido personajes especialmente relevantes en la historia española, ${ }^{11}$ con la excepción de Eduardo Barriobero y de Milà i Fontanals. Dejaremos a un lado los traductores anónimos, los traductores prácticamente desconocidos (Tomás H. de las Torres) o los que se valieron de un seudónimo (Fray C. Alegre). Los restantes pueden ser agrupados según su actividad o su ideología:

- Varios fueron autores - a veces prolíficos — de novelas e incluso de ensayos, y sobre todo traductores de numerosas obras literarias (principalmente escritas en francés) probablemente por motivos sólo pecuniarios: Leopoldo García-Ramón, Luis Francisco Obiols, Germán Gómez de la Mata, Antonio R. García Vao, Juan G. Olmedilla; en este grupo puede insertarse también con cierta singularidad Manuel Aranda y Sanjuán, carente de obra literaria propia, pero traductor profesional de autores italianos clásicos y modernos (Ariosto, Dante, Manzoni, De Amicis, además de Boccaccio). Un caso particular es el de Luis Larrañaga, polígrafo vasco que se ocupó de los más variados temas, a veces bajo el seudónimo Luis de Bizkaya, y cuya única traducción conocida es precisamente la de Boccaccio.

11. Para obtener noticias más detalladas de estos traductores debe consultarse el Catálogo del Proyecto Boscán (apartado Traductores): Proyecto Boscán: Catálogo de las traducciones españolas de obras italianas (hasta 1939) [en línea]. <http://www.ub.edu/boscan> [28 de agosto de 2007]. 
- Las adaptaciones al teatro musical son todas anónimas, con la excepción de dos, firmadas por un prolífico autor de libretos de la época: Fiacro Yrayzoz.

- Varios de los traductores ostentaron una ideología republicana o incluso revolucionaria, que les llevó al exilio o a la muerte: Antonio R. García Vao (asesinado en 1888), Juan G. Olmedilla (exiliado en Argentina tras la Guerra Civil), Eduardo Barriobero (fusilado por los franquistas en 1939). Este último es el único traductor boccacciano que gozó de notoriedad pública por su actividad como diputado en la Cortes republicanas y Presidente un tiempo del Partido Republicano Federal. Como traductor, sus ideas heterodoxas se reflejan en las versiones del francés (Rabelais, Voltaire, Lorulot; los rusos Dostoyevsky y Bezsonov), del italiano (además del Decameron, dos novelas de Guido da Verona), del latín (Luciano, Ovidio) y del catalán (La disputa de l'ase del renegado Anselm Turmeda).

- Singular es también el caso de Manuel Milà i Fontanals, profesor de literatura de la Universidad de Barcelona y notable filólogo, que como traductor de la literatura italiana acumuló, además del breve experimento boccacciano, notables versiones fragmentarias de Dante (Divina commedia y Vita nova), un «himno sacro» de Manzoni (La Passione) y otras obras completas en colaboración: Dei doveri degli uomini de Pellico y Gli Animali parlanti de Casti. $^{12}$

\section{Los editores}

Entre las editoriales que incorporaron el Decameron a su catálogo de títulos, encontramos algunas que tuvieron una cierta relevancia en su época. Nos centraremos sobre todo en las que publicaron versiones íntegras de la obra.

De todas ellas la más importante es probablemente la casa editorial barcelonesa Maucci, nacida en 1892 por iniciativa de un editor originario de Toscana, Emanuele Maucci, que anterioremente había ejercido su profesión en Hispanoamérica. Su fondo editorial llegó a contar con cientos de títulos de los más variados temas (especialmente narrativa, tanto española como extranjera, poesía, divulgación científica, etc.). Se trata de una más de las muchas editoriales de tipo popular que hicieron negocio aprovechando el acceso a la lectura por parte de muchos españoles sacando al mercado ediciones económicas de muy baja calidad material y grandes tiradas. Maucci contribuyó a difundir en España numerosos autores extranjeros, en traducciones que, sin embargo, no fueron de gran calidad, al estar hechas por traductores poco diestros y muy mal pagados. ${ }^{13}$ Esta editorial publicó ya en 1898 un librito con la traducción de dos novelle del Decameron (cuyo texto está tomado — sin decirlo- de la publicada también anónimamente en 1876). No sabemos si por el

12. Ma de las Nieves MuÑIZ MuñIZ, "Manuel Milà i Fontanals, traductor clandestí de Giambattista Casti», Els Marges, 2005, n. 76, p. 69-78.

13. Manuel LlanAS, "Notes sobre l'editorial Maucci i les seves traduccions», Quaderns. Revista de traducció, n. 8, 2002, p. 11-16. 
éxito obtenido o por otro motivo la propia Maucci publicó seis años más tarde una edición íntegra e independiente de todas las hechas con anterioridad, que, por otra parte, es la que más se ha difundido en español hasta la aparición de otras nuevas a partir de los años sesenta del siglo XX.

Otra editorial de prestigio que acogió la obra de Boccaccio entre sus fondos fue Prometeo, fundada por el escritor Vicente Blasco Ibáñez en 1914, ${ }^{14}$ sobre la base de la precedente editorial Sempere. El proyecto de Blasco es similar al de Maucci - la edición popular-, aunque con una ideología progresista mucho más marcada, que se refleja en su catálogo, formado también por centenares de obras, sobre todo de tipo literario, con muchas traducciones del francés, aunque con una edición más cuidada de los textos. Blasco era consciente de la competencia que suponía Maucci, a la que despreciaba y al mismo tiempo temía. ${ }^{15}$ Sin embargo, tampoco Prometeo parece haberse distinguido por sus buenas prácticas editoriales ni por un trato exquisito a los traductores. La editorial publicó una treintena de traducciones del italiano, fundamentalmente de autores contemporáneos. Destaca sobre todo por haber sido la primera en difundir en forma impresa en España las obras teatrales de Pirandello. Nada sabemos de los motivos que empujaron a Prometeo a publicar la traducción del Decameron, última por cierto entre las hechas del italiano y que, por otra parte, se aleja de la línea (contemporánea) seguida en aquellos años. Blasco, ya célebre, había cedido a otros el control de la editorial muchos años antes; su muerte, como es sabido, se produjo en Francia ese mismo año (1928).

Los hermanos Garnier de París publicaron tres ediciones de la traducción española del Decameron entre 1882 y 1890 que debieron ser bien conocidas en España. Esta editorial desempeñó un papel importante en la difusión de varios autores italianos, entre los que destacan Machiavelli, Manzoni, Pellico y Cantù.

Cabe mencionar por último la revista literaria Novelas y Cuentos, una de las más populares del siglo XX, que llegó a editar cientos de obras entre 1929 y 1966. Entre los autores italianos allí incluidos se cuentan Machiavelli y Bandello, además de Boccaccio, dentro de los antiguos; Manzoni, Pellico y Serao, dentro de los modernos.

14. Para noticias más detalladas de esta editorial véanse: Ma José FulLana MonTORO, La editorial Prometeo. Sociología del libro valenciano de principios del siglo XX. Tesis de Licenciatura. Universitat de València, curso 1982-83; Manuel BAS CARBONELL, "Aproximación al catálogo de la Editorial Prometeo", en Blasco Ibáñez: y el periodismo se hizo combativo, Valencia: Diputación de Valencia, 1998, p. 97-103; Cesáreo Calvo RiguaL, «La traducción de obras literarias italianas en las editoriales Sempere y Prometeo (1900-1936)», en La traducción de los clásicos: problemas y perspectivas. Actas de los X Encuentros Complutenses en torno a la Traducción, ed. de M. A. Vega Cernuda, Madrid: Editorial Complutense (Instituto de Traductores), 2005, p. 129-145.

15. "... hay una inmensa masa que nunca la hemos tenido y que se nutre con los folletines de los periódicos, los mamarrachos de Maucci y un resto que queda aún de las novelas por entregas» (Miguel Herráez (ed.), Epistolario de Vicente Blasco Ibánez-Francisco Sempere (1901-1917). Valencia: Generalitat Valenciana-Consell Valencià de Cultura, 1999, p. 106-107). 


\section{Las traducciones}

Un acercamiento a las traducciones mismas ${ }^{16}$ se hace necesario si queremos arrojar luz sobre dos aspectos relevantes que explican la forma en la que el común de los lectores españoles leyó el Decameron durante casi un siglo. Las preguntas a las que trataremos de responder son las siguientes: por un lado, qué relación guardan con el original italiano y con otras traducciones existentes; por el otro, cuál es su calidad en términos estilísticos.

Si bien el espacio de que disponemos y el gran número de versiones no permiten realizar un estudio en profundidad, intentaremos ofrecer algunas muestras significativas de un análisis más extenso para trazar un perfil orientativo.

Desde el punto de vista de las dependencias textuales con respecto al original o a otras versiones, se aprecian cuatro grupos:

a) Traducciones directas, es decir realizadas sobre el texto original italiano: [1875], [1888a], [1904].

b) Traducciones indirectas, es decir realizadas sobre una traducción francesa: [1865], [1876], [1884b], [1924].

c) Traducciones mixtas: [1925], es decir, basadas en otras (la de 1876 o la de 1882), pero con el original italiano o una traducción más fiel delante (la de 1928).

d) Plagios de traducciones anteriores:
a. De [1876] o [1882]: [1882], [1898], [1932]. ${ }^{17}$
b. De [1904]: [1920] (compendio), [1921], [1933]. ${ }^{18}$

16. No nos ocuparemos de las adaptaciones en verso o para el teatro, por ser, como hemos dicho, recreación libérrima de simples motivos de Boccaccio.

17. M. HERnÁNDEZ, «Dos antologías madrileñas...» cit., p. 163 y ss., atribuye el "particular» modo de traducir de Barriobero a diferentes motivos («se traduce con soltura»; «ante las dificultades el traductor sale al paso suprimiendo, inventando o imaginando, como era usual en la época", «el traductor suprime equívocos de doble sentido», etc.), cuando en realidad no hace más que copiar, añadiendo en ocasiones algún comentario, la traducción que se hizo del francés en 1876 (o de una de sus secuelas posteriores). Probablemente — pues de una antología declaradamente erótica se trata-, Barriobero hubiera traducido gustosamente todas las referencias eróticas que el traductor francés eliminó de su versión. El varias veces citado Proyecto Boscán tiene entre otras muchas indudables utilidades la de ofrecer una visión de conjunto de las traducciones de un autor a lo largo de la historia, aunque se va mucho más allá en ciertos casos en los que los investigadores han podido, como en éste, determinar con precisión el recorrido textual por el que ha transitado el original hasta llegar a las manos de los lectores españoles. Por otra parte, en los siglos en los que el dominio del francés y la cultura francésa tuvieron una relevancia tan decisiva, no se debe descartar en numerosos casos - dejamos de lado obviamente aquellos que lo declaran explícitamente- que las traducciones se hayan hecho a partir de traducciones francesas, mucho más accesibles para las personas cultas de dichos períodos. El caso de las traducciones del Decameron aquí estudiadas puede considerarse paradigmático.

18. Lo dicho para la traducción de [1932] en la nota anterior, se puede decir, mutatis mutandis, para la de [1933], que tampoco es una traducción original sino un plagio. 
Tomaremos como campo de pruebas en primer lugar III 1, al ser la novella más veces traducida, seguida de I 4, IV 5 y VII $7 .{ }^{19}$ Comenzaremos con los títulos dados a algunas novelle:

III 1 Masetto da Lamporecchio si fa mutolo e diviene ortolano d'un monistero di donne, le quali tutte concorrono a giacersi con lui

(francés) ${ }^{20}$ Maset de Lamporecchio ou le paysan parvenu

1876 Masetto de Lamporecchio o el campesino afortunado

1882 Masetto de Lamporecchio o el campesino afortunado

1898 Masetto de Lamporecchio o el campesino afortunado

1904 Masetto de Lamporecchio se finge mudo, y llega a ser hortelano de un monasterio de mujeres, todas las cuales le otorgan sus favores

1924 Masetto de Lamporecchio o el jardinero afortunado

1925 El jardinero mudo, las ocho hermanas y la madre

1928 Masetto de Lamporecchio se finge mudo y entra de hortelano en un monasterio de monjas, todas las cuales hubieron de yacer con él

La dependencia de la traducción francesa resulta evidente en [1876], [1882], [1898] y [1924]. Mientras que [1904] y [1928] dependen del texto italiano original. [1925], en cambio, ofrece un título algo disparatado, en sintonía con el tipo de traducción-apropiación que ofrece.

IV 5 I fratelli d'Ellisabetta uccidon l'amante di lei; egli l'apparisce in sogno e mostrale dove sia sotterrato; ella occultamente disotterra la testa e mettela in un testo di bassilico; e quivi sú piagnendo ogni dí per una grande ora, i fratelli gliele tolgono, e ella se ne muore di dolor poco appresso.

(francés) Le basilic salernitain

1876 La albahaca salernitana

1882 La albahaca salernitana

1888 Amor después de la muerte

1904 Los hemanos de Isabel matan al amante de su hermana: éste se le aparece en sueños y la indica el sitio donde está enterrado. Ella

19. Esta selección abarca todas las traducciones en prosa al castellano.

20. Se cita la traducción de Antoine Sabatier de Castres (1742-1817) publicada por primera vez en 1779. Los hermanos Garnier de París publicaron repetidas veces esta traducción a partir de 1850. Citamos por la edición de 1869. La traducción de [1882] copió de ella parte de las ilustraciones. 
desentierra ocultamente la cabeza y la coloca en un tiesto de albahaca; y llorando encima de él cada día durante largo rato, los hermanos se lo quitan, y ella muere de dolor

1920 El tiesto de albahaca de la bella Isabel

(1928) Los hermanos de Isabel matan al amante de la joven, el cual se la aparece en sueños y le indica el lugar donde está sepultado; ella desentierra a escondidas la cabeza y la pone en un tiesto de albahaca; pero, como a diario llora junto al tiesto, se lo quitan sus hermanos, é Isabel muere de pena en seguida

Se repite la tónica anterior, a excepción de [1920], que como norma da a las novelle títulos descriptivos.

El inicio de III 1 pone de manifiesto la dependencia tanto del original italiano, como de la versión francesa y de otras traducciones:

III 1, 6 In queste nostre contrade fu e è ancora, un munistero di donne assai famoso di santità (il quale io non nomerò per non diminuire in parte alcuna la fama sua), nel quale, non ha gran tempo, non essendovi allora più che otto donne con una badessa, e tutte giovani, era un buono omicciuolo d'un loro bellissimo giardino ortolano: il quale, non contentandosi del salario, fatta la ragion sua col castaldo delle donne, a Lamporecchio, là onde egli era, se ne tornò.

(francés) Il y a dans notre pays un monastère de filles qui fut autrefois célèbre par sa saintenté. Il n'y a pas encore longtemps qu'il n'était composé que de huit religeuses, sans y comprendre madame l'abbesse. Elles avaient alors un très-beau jardin et un très-bon jardinier. Il prit fantaisie un beau matin à ce jardinier de les quitter, sous prétexte que les gages qu'on lui donnait n'étaient pas assez forts. Il va donc trouver leur intendant, lui demande son compte et s'en retourne au village de Lamporechio, sa patrie.

1876 Hay en nuestro país un monasterio de mujeres, célebre en otra 1882 época por su santidad. No hace todavía mucho tiempo que la 1898 comunidad se componia de ocho monjas, sin contar la madre abadesa, teniendo en aquel entonces un huerto muy lindo y un hortelano excelente. Un día se le antojó al tal jardinero abandonar las monjas, bajo el pretexto de que el sueldo que se le daba era mezquino. Así pues, dirígese en busca del intendente, pídele que se le arregle su cuenta y regresa al pueblo de Lamporecchio, su patria.

1904 En este nuestro país, hubo y hay todavia, un monasterio de muje1921 res con bastante fama de santidad (que no nombraré, para no disminuir en parte alguna su fama), en el cual hace poco tiempo que, 
no habiendo más que ocho mujeres con una abadesa, y todas jóvenes, había un buen hombrecillo que cuidaba de su hermosísimo jardín, y que, no estando contento con el salario, arregló sus cuentas con el mayordomo de las monjas y regresó a Lamporecchio de donde era natural.

1924 Hay en nuestro país un monasterio de monjas, que en otra época alcanzó gran celebridad por lo muy estrecho de su regla y la gran santidad de vida. No hace mucho que este convento existía aún, y la Comunidad estaba compuesta por ocho monjas, sin contar la madre abadesa. El monasterio tenía un huerto muy hermoso, que estaba muy bien cuidado por un excelente hortelano. Pero ocurrió un día que el jardinero, cansado de su oficio, con el pretexto de que su salario era mezquino, abandonó para siempre el convento de las monjas. Entrevistóse con el intendente, pidió su cuenta, y una vez recibido el dinero, se dirigió a Lamporecchio, su pueblo natal.

1925 Habia en Italia, en tiempos cercanos a los del Decamerón, un convento de mujeres célebre por la santidad con que eran observadas sus reglas. Boccacio no lo cita en su historieta - la primera de la tercera parte- por no amenguar la fama del tal monasterio; mejor dicho: por no trocar aquel buen nombre de edificante en libertino, ya que la fama el convento habríala cobrado centuplicada e imperecedera si el comentarista se decide, indiscreto, a estampar su nombre en las páginas del Decamerón inmortal. [...]

1928 Hay en nuestro país un monasterio de mujeres que fue célebre otrora por su santidad. Todavía no hace mucho tiempo, estaba compuesto sólo de ocho jóvenes religiosas, sin contar a la abadesa. Tenían entonces un huerto muy hermoso y un hortelano muy bueno, a quien un día le dio la ventolera por dejarlas, so pretexto de que su salario no era remunerador. Fue, pues, a ver al mayordomo de las monjas, le pidió su cuenta y regresó a Lamporecchio, su pueblo.

1932 Existe en nuestro país un monasterio de mujeres, célebre un tiempo por su santidad. No ha mucho tiempo que la comunidad se componia de ocho monjas, a más de la madre abadesa, teniendo en aquel entonces un huerto en extremo lindo y un hortelano excelente. Se le antojó un día al citado jardinero abandonar a las monjas, bajo el pretexto de que el sueldo que se le daba era mezquino. Así, pues, dirígese en busca del intendente, pídele que le arregle su cuenta y regresa al pueblo de Lamporecchio, su patria. 
- Las notables modificaciones introducidas en la traducción de [1876] ${ }^{21}$ (cambio de perspectiva temporal: $f u$ > «hay», se ne tornò > "dirígese»; supresiones: como el inciso il quale io non nomerò per non diminuire in parte alcuna la fama sua o datos relevantes: otto donne con una badessa, e tutte giovani; desafortunados añadidos: "teniendo en aquel entonces un huerto muy lindo y un hortelano excelente»; amplificaciones: il quale, non contentandosi del salario, fatta la ragion sua col castaldo delle donne > "Un día se le antojó al tal jardinero abandonar las monjas, bajo el pretexto de que el sueldo que se le daba era mezquino. Así pues, dirígese en busca del intendente, pídele que se le arregle su cuenta»; etc.), se explican al comprobar que esta versión siguió la falsilla del texto francés de Sabatier de Castres. Ello supuso no sólo cercenar el marco narrativo, sino también simplificar drásticamente la sintaxis despiezando el complejo período boccacciano. El hecho de no haber tenido el original a la vista acentúa el estropicio general, lo cual es tanto más grave cuanto que se trata de la primera traducción moderna completa del Decameron al alcance de los lectores del siglo XIX.

- [1924] y [1928] resultan también claramente dependientes del mismo texto francés, aunque no de [1876]. En la primera abundan los excursos, incisos y comentarios: «alcanzó gran celebridad por lo muy estrecho de su regla y la gran santidad de vida», "que este convento existía aún», "que estaba muy bien cuidado»... En cuanto a la segunda, veremos pronto que el procedimiento fue más complejo.

- [1925] constituye, como hemos dicho, un caso particular: sus caracterísiticas hacen pensar que Olmedilla partió seguramente de [1876], aunque otros detalles (como la frase "por no amenguar la fama del tal monasterio", que no está ni en aquella traducción ni en la versión francesa) permiten suponer que tuvo delante también el texto original italiano.

- [1932] no es más que un plagio de [1876], con muy escasas variantes (pequeños cambios de palabras, amplificaciones, algunas supresiones...: «Existe», «No ha mucho tiempo», «un huerto en extremo lindo», «Se le antojó un día al citado jardinero»). En otros fragmentos la principal diferencia consiste en la adición de comentarios inexistentes tanto en el original y como en [1876].

— [1904], resulta ser la única traducción fiel y directa del texto italiano.

El caso de [1928] es especialmente intrigante, porque junto a fragmentos en los que claramente sigue el texto francés, en otros se atiene al original italiano. Ello ocurre, como hemos visto, en los títulos, pero a menudo el contenido del relato responde a una técnica híbrida. Así el siguiente pasaje coincide básicamente con la versión francesa, pero inserta aquí y allá expresiones cuyo equivalente hallamos sólo en el original (vid. cursivas):

21. Lo dicho para esta versión vale también para [1882] y [1898], que son meros plagios de ella. 
IV 5, 4-5 Erano adunque in Messina tre giovani fratelli e mercatanti, e assai ricchi uomini rimasi dopo la morte del padre loro, il qual fu da San Gimignano; e avevano una loro sorella chiamata Elisabetta, giovane assai bella e costumata, la quale, che che se ne fosse cagione, ancora maritata non aveano. E avevano oltre a ciò questi tre fratelli in uno lor fondaco un giovinetto pisano chiamato Lorenzo, che tutti i lor fatti guidava e faceva, il quale, essendo assai bello della persona e leggiadro molto, avendolo più volte Lisabetta guatato, avvenne che egli le incominciò stranamente a piacere. Di che Lorenzo accortosi e una volta e altra, similmente, lasciati suoi altri innamoramenti di fuori, incominciò a porre l'animo a lei; e sì andò la bisogna che, piacendo l'uno all'altro igualmente, non passò gran tempo che, assicuratisi, fecero di quello che più disiderava ciascuno.

(francés) Il y avait autrefois à Messine trois frères, marchands, qui demeurèrent très-riches après la mort de leur père, né à San-Geminiano. Ils avaient une soeur, jeune, belle et bien faite, nommée Isabeau, quils n'avaient pas encore mariée, quoiquils en eussent souvent trouvé l'occasion. Ils avaient aussi pour garçon de boutique un jeune homme de Pise, nommé Laurent, sur qui roulaient presque toutes les affaires de leur négoce. Ce commis était d'une figure agréable et d'un caractère plein de douceur. La charmant Isabeau en devint amoureuse. Laurent s'en aperçut, en fut très-flatté, et renonça, pour sa nouvelle conquête, à ses autres maîtresses. Comme ils étaient à portée de se voir et de se parlar fort souvent, ils ne furent pas longtemps à se donner des preuves de tendresse.

1928 Había, pues, en Messina, tres hermanos mercaderes, que hubieron de quedar bastante ricos en plena juventud a la muerte de su padre, natural de San Geminiano. Tenían una hermana llamada Isabelita, joven también y hermosa a más de bien criada, a la cual no habian hecho matrimoniar aún por razones que no son del caso. Regentaba la tienda de los tres un jovencillo pisano que atendía por el nombre de Lorenzo, llevando el peso de todos los negocios de la casa. Y como era buen mozo y galante, Isabelita se prendó de él a fuerza de verle, lo que le hizo renunciar a sus otros amores para consagrarse sólo al de ella en cuanto hubo de advertirlo; de modo que no tardaron mucho en darse pruebas reciprocas de sus sentimientos comunes.

Entre otras cosas, el traductor español corrige el error del francés (che che se ne fosse cagione > "quoiqu'ils en eussent souvent trouvé l'occasion») restaurando el correcto sentido: "por razones que no son del caso».

Véase ahora dos diferentes traducciones del mismo fragmento (IV 5), correspondientes a [1888a] y [1920]: 
1888a Vivían en Mesina tres jovenes hermanos comerciantes, cuyo padre les había legado al morir una pingüe herencia. Tenían éstos una hermana, llamada Isabel, joven donosa y modesta, a la que aun no habian casado, por más que no faltaran pretendientes a su mano. Los tres hermanos tenían además como dependiente en una tienda suya, a un mancebo de Pisa, llamado Lorenzo, que estaba al frente de todos sus negocios, y que siendo un joven apuesto y placentero, llamó la atención de Isabel, la cual a fuerza de mirarle, acabó por enamorarse de él. No pudo menos de conocer Lorenzo el efecto que inspiraba a la joven, y abandonando todos sus amoríos, empezó a corresponder al cariño de Isabel, de suerte que, gustándose al fin el uno al otro, se declararon mutuamente su pasión, e hicieron lo que cada uno de ellos deseaba.

1920 Había en Mesina tres jóvenes hermanos, comerciantes, que habían quedado bastante ricos después de la muerte de su padre, los cuales vivían con su hermana Lisabetta, joven muy hermosa y muy bien educada, a la que, fuera por lo que fuese, no habian casado aún. Regentaba la tienda de los hermanos un joven llamado Lorenzo, bastante guapo y muy galante, que se enamoró de Lisabetta, siendo por ella correspondido;

La traducción de Aranda [1888a] parece hecha sobre el original, tal como reza su título, aunque en casos como «a la que aun no habían casado, por más que no faltaran pretendientes a su mano» parece seguir el francés («qu'ils n'avaient pas encore mariée, quoiqu'ils en eussent souvent trouvé l'occasion») y no el italiano ("la quale, che che se ne fosse cagione, ancora maritata non aveano»). Sin embargo, al hablar de la conclusión carnal de sus amores («e hicieron lo que cada uno de ellos deseaba») regresa al original italiano («fecero di quello che più disiderava ciascuno»), descartando el eufemismo del francés («à se donner des preuves de tendresse»). La continuación del pasaje despeja cualquier duda sobre la filiación de la traducción, aunque ésta resulte amplificada innecesariamente repitiendo el detalle del hermano.

En cuanto a la de Larrañaga [1920], sorprende ante todo su brevedad, resultante de la técnica compendiadora del original aplicada a toda la obra.

La traducción de [1884b] se limita, como hemos dicho, a una sola novella (I 4) y no es difícil constatar que está hecha a partir del texto francés publicado por Garnier, aunque el carácter literal de la retraducción llevada a cabo en [1876], no permite excluir que haya sido ésta el texto fuente y que el plagio se disimulase con la inserción de variantes:

I 4, 4 Fu in Lunigiana, paese non molto da questo lontano, uno monistero già di santità e di monaci più copioso che oggi non è, nel quale tra gli altri era un monaco giovane, il vigore del quale né la freschezza né i digiuni né le vigilie potevano macerare. 
(francés) Dans le pays de Lunigiane, qui n’est pas fort éloigné du nôtre, se trouve un monastère dont les religeux étaient autrefois un exemple de dévotion et de sainteté. Vers le temps qu'ils commençaient à degenerer, il y avait parmi eux un jeune moine, entre autres, dans qui les veilles et les austérites ne pouvaient réprimer l'aguillon de la chair.

1876 En el país de la Lunigiana, no muy distante del nuestro, existe un monasterio cuyos religiosos eran antes modelo de devoción y santidad. Hácia [sic] el momento en que comenzaron a degenerar, vivía entre ellos un jóven monje, entre otros, en el quel las vigilias y austeridades no lograban reprimir el aguijón de la carne.

1884b En el territorio de Lunigiana, cercano al nuestro, existe un monasterio cuyos religiosos, en otro tiempo, sólo se dedicaban a las prácticas de la devoción y de la santidad. Por la época en que comenzaron a apartarse del buen camino, vivía entre ellos un monje de edad temprana, más inclinado a los goces carnales que a las dulzuras del misticismo.

Los cambios, que señalamos en cursiva, apuntan tanto al subtexto francés como al español de [1876] (que citamos uno a continuación de otro, separados por barra): «pays»/ «país» > «territorio»; «qui n’est pas fort éloigné»/ «no muy distante» > "cercano»; "se trouve un monastère dont les religieux étaient autrefois un exemple de dévotion et de sainteté»/ "existe un monasterio cuyos religiosos eran antes modelo de devoción y santidad» > «existe un monasterio cuyos religiosos, en otro tiempo, sólo se dedicaban a las prácticas de la devoción y de la santidad»; «Vers le temps qu’ils commençaient à degeneren»/ «Hácia el momento en que comenzaron a degenerar» > "Por la época en que comenzaron a apartarse del buen camino»; "il y avait parmi eux un jeune moine» / "vivía entre ellos un jóven monje» > "vivía entre ellos un monje de edad temprana»; "dans qui les veilles et les austérites ne pouvaient réprimer l'aguillon de la chair»/ «en el quel las vigilias y austeridades no lograban reprimir el aguijón de la carne» > "más inclinado a los goces carnales que a las dulzuras del misticismo".

Las dos versiones catalanas de Milà i Fontanals siguen el texto original italiano prácticamente palabra por palabra, como podrá comprobarse cotejando el inicio de la breve novella I 9:22

I 9, 4 Dico adunque che né tempi del primo re di Cipri, dopo il conquisto fatto della Terra Santa da Gottifrè di Buglione, avvenne che una gentil donna di Guascogna in pellegrinaggio andò al Sepolcro, donde tornando, in Cipri arrivata, da alcuni scellerati uomini villanamente fu oltreggiata. Di che ella senza alcuna consolazion dolendosi, pensò 
d'andarsene a richiamare al re; ma detto le fu per alcuno che la fatica si perderebbe, per ciò che egli era di sì rimessa vita e da sì poco bene, che, non che egli l'altrui onte con giustizia vendicasse, anzi infinite con vituperevole viltà a lui fattene sosteneva, in tanto che chiunque aveva cruccio alcuno, quello col fargli alcuna onta o vergogna sfogava.

1875 Dich donchs qu'en lo temps del primer Rey de Xipre, apres la (catalán conquesta de la Terra Santa per Godofré de Bulló, esdevingué que literario) una gentil dona de Gasconya aná peregrinant al Sant Sepulcre, de ahont tornant y arribada a Xipre fou villanament ultrajada per altuns homes malvats, de lo que ella dolents'en sens consol, pensá d'anars'en al Rey á reclamar; mes dit li fou per algú que's perdria la fatiga, per so qu'ell era de vida tan fluixa y de tan poca bondat que no solament no venjava ab justicia los oprobis dels altres, ans en sofria ab vituperable vilesa infinits á ells fets; de manera que qui tenia algun motiu de ira lo desfogava fentli algun oprobi o vergonya.

La traducción de [1933] plagia ad litteram la de Obiols de [1904], limitándose a abreviar al máximo los títulos que allí reproducían las largas rúbricas del original:

IV 4 Gerbino, contra la fede data dal re Guiglielmo suo avolo, combatte una nave del re di Tunisi per torre una sua figliuola; la quale uccisa da quegli che sú v'erano, loro uccide, e a lui è poi tagliata la testa.

(francés) La fiancée du roi de Grenade ou les amants infortunés.

1904 Gerbino, faltando a la palabra dada al rey Guillermo, su abuelo, ataca una nave del rey de Túnez, para apoderarse de una hija suya, y como los del bique la dan la muerte, mátales él, y a él después le es cortada la cabeza.

1933 El trágico amor de Gerbino.

IV 4, 4 Guiglielmo secondo, re di Cicilia, come i ciciliani vogliono, ebbe due figliuoli, l'uno maschio e chiamato Ruggieri, l'altro femina, chiamata Gostanza. Il quale Ruggieri, anzi che il padre morendo, lasciò un figliuolo nominato Gerbino, il quale, dal suo avolo con diligenzia allevato, divenne bellissimo giovane e famoso in prodezza e in cortesia.

(francés) Guillaume II, roi de Sicile, eut deux enfants: un garçon, nommé Roger, et une fille, appelée Constance. Roger mourut avant son père. Il laissa un fils, qui portait le nom de Gerbin, que le grandpère fit élever avec beaucoup de soin. Ce jeune homme devint un prince accompli. 
1904 Guillermo II, rey de Sicilia, según afirman los sicilianos, tuvo dos hijos: uno varón llamado Ruggieri y otra hembra llemada [sic] Costanza. Ruggieri, muriendo antes que su padre, dejó un hijo llamado Gerbino, cuyo hijo, cuidadosamente criado por su abuelo, llegó a ser un bellísimo joven, famoso en proezas y cortesía.

1933 Guillermo II, rey de Sicilia, según afirman los sicilianos, tuvo dos hijos: uno varón llamado Ruggieri y otra hembra llamada Costanza. Ruggieri, muriendo antes que su padre, dejó un hijo llamado Gerbino, cuyo hijo, cuidadosamente criado por su abuelo, llegó a ser un bellísimo joven, famoso en proezas y cortesía.

La última ${ }^{23}$ de las traducciones reseñadas es la de [1865], que al igual que otras posteriores se basó en el mismo texto francés, ${ }^{24}$ como puede comprobarse tan solo comparando el final de la única novella traducida:

IV 4 per la qual cosa, come che poi più volte con Anichino e egli e la donna ridesser di questo fatto, Anichino e la donna ebbero assai agio di quello per avventura avuto non avrebbeno a far di quello che loro era diletto e piacere, mentre a Anichin piacque dimorar con Egano in Bologna.

(francés) Béatrix et son amoureux rirent plus d'une fois de cette scène singulière. Laveugle prévention du mari les mit dans le cas de se voir en toute liberté. Et ils en profitèrent pour moltiplier leurs jouissances tout le temps qu'Hannequin demeura à Florence, d'où il ne partit que pour aller a Jérusalem.

1865 Beatriz y Hanaquin reian siempre que se acordaban de esta singular escena; y la confianza que hizo el marido de ellos, les dió mas libertad para entregarse á sus apasionados y sabrosísimos trasportes, hasta que Hanaquin volvió á Francia de donde no salió sino para ir á Jerusalen.

1924 Beatriz y su amante se reían no pocas veces de la graciosa aventura, y gracias a la ciega confianza del marido, podían verse con completa libertad. Y no perdieron día mientras Anichino permaneció en Bolonia, hasta su partida para Jerusalén.

Una vez desenredada la maraña textual de este conjunto de traducciones no queda sino comentar brevemente algunos rasgos de la técnica seguida en

23. Esta traducción es la descubierta más recientemente (por Ma de las Nieves Muñiz), y al mismo tiempo la más antigua — si dejamos de lado las adaptaciones en versos- entre las traducciones modernas del Decameron.

24. También el título denuncia esta dependencia: «Le mari cocu, battu et content»/ «El marido engañado, apaleado y contento». 
ellas. Nos limitaremos a analizar algunos aspectos significativos, como son el tratamiento del tema erótico y el anticlerical, que, como veremos, distingue claramente la estrategia adoptada en cada versión (obviamente la cuestión de la fidelidad queda fuera de análisis en el caso de las versiones indirectas y de los plagios).

La frase con la que se concluye la novella de Masetto es un caso paradigmático, con su expresión blasfema, que pone a prueba a traductores y editores: ${ }^{25}$

III 1, 43 Così adunque Masetto vecchio, padre e ricco, senza aver fatica di nutricare i figliuoli o spesa di quegli, per lo suo avvedimento avendo saputo la sua giovanezza bene adoperare, donde con una scure in collo partito sera se ne tornò, affermando che così trattava Cristo chi gli poneva le corna sopra'l cappello.

(francés) [...] C'est ainsi que le ciel récompense ceux qui bêchent et arrosent infatigablement le jardin altéré des pauvres nonnains.

1876 [...] De esta suerte recompensa el cielo a los que labran y riegan

etc. infatigablemente el sediento jardín de las pobres monjas.

$1904 \quad[\ldots]$

1924 [...] Así premia el Cielo a los que en esta vida cavan y riegan el sediento jardín de las monjitas.

$1925[\ldots]$

1928 [...]

1932 [...] Así recompensa el cielo a los que, sin descanso, labran y riegan el sediento jardín de las míseras monjas.

Tanto los que han seguido el texto francés (que ya en origen modifica eufemísticamente la expresión) como quienes traducen directamente del italiano evitan la expresión. A pesar de que en algunos casos se trata de traducciones en las que se quiere vender precisamente lo escandaloso, a la hora de la verdad es mayor el peso de la censura o de la autocensura en una sociedad tan puritana como la española de la época.

25. Como curiosidad señalamos que tampoco la traducción catalana medieval la traduce: «E Masseto, qui ja era veyll, ach desitg de tornar entre sos amichs. Axí, doncs, Maseto, assats ric e pare de molts fiyls nodrits sens treball, havent sabut de hobrar en sa joventut, exint de sa terra pobre e $\mathrm{ab}$ una destral al coll, aprés molt temps s'entornà rich e bent anant entre sos amics e parents. E veus quin guardó ret nostre Senyor en aquells qui en tal manera servexen e fan bones hobres»; la antigua traducción castellana, en cambio, no siente ningún reparo en hacerlo: «De manera que maseto padre viejo \& rico syn hauer fatiga de mantener jijos \& cosa de casa el tiempo venidero hauiendo muy bien sabido la su mocedad despender que con vna habha al hombro era ally venido rico \& de buena ventura a su tierra de lampolechio se torno affirmando que anssy tractaua a christo que le ponia los cuernos encima del sombrero». 
En el fragmento siguiente de la misma novella aparece una clara referencia sexual, y la estrategia traductoria se repite sustancialmente:

III 1,20 [...] Il quale lavorando l'un dì appresso l'altro, le monache incominciarono a dargli noia e a metterlo in novelle, come spesse volte avviene che altri fa de' mutoli, e dicevangli le più scellerate parole del mondo, non credendo da lui essere intese; e la badessa, che forse stimava che egli così senza coda come senza favella fosse, di ciò poco o niente si curava.

(francés) [...] L'abbesse, simmaginant quill n'était pas plus à craindre du nerf viril que de la langue, ne s'en mettait guère en peine

1876 [...] A la abadesa, creyendo que era tan poco temible del nervio viril como de la lengua, no le preocupaba la conducta de las monjas.

1904 [...] y sin que la abadesa [omissis] poco o nada se preocupase de ello.

1924 [... L La abadesa, que lo creía tan inofensivo por el nervio viril como por la lengua, no ponía gran atención en las burlas de las religiosas.

1925 [...] la abadesa, creyendo que sería tan poco temible del miembro viril como lo era de la lengua [...]

1928 [...] sin que la abadesa [omissis] reparara en ello.

1932 [...] A la abadesa, creyendo que era tan poco temible del nervio viril como de la lengua, no le preocupaba la conducta de las monjas. ${ }^{26}$

Las traducciones de [1876], [1924] y [1932], siguiendo el texto francés («nerf viril»), traducen nervio viril, que resulta comprensible pese a su inexistencia en español, mientras que [1904] y [1928] censuran la expresión.

En lo que respecta a las otras traducciones, haremos algunas catas tomadas de otros cuentos. En I 4, el abad, en lugar de amonestar al monje que ha conducido a su celda a una jovencita, opta por gozar también de ella:

I 4, 15-16 "Deh, perché non prendo io del piacere quando io ne posso avere, con ciò sia cosa che il dispiacere e la noia, sempre che io ne vorrò, sieno apparecchiati? Costei è una bella giovane è è qui che niuna persona del mondo il sa; se io la posso recare a fare i piacer miei, io non so perché io nol mi faccia. Chi il saprà? Egli nol saprà persona mai, e peccato celato è mezzo perdonato. Questo peccato non avverrà forse mai più: io estimo ch'egli sia gran senno a pigliarsi del bene, quando Dome-

26. Sigue una frase que falta tanto en la versión francesa como en el texto italiano, que no es más que una intervención extemporánea del traductor Barriobero: «Masetto sabía desempeñar demasiado bien su papel para no pasar por un tonto rematado a los ojos de las religiosas, esperando poder desengañar a alguna de su error, cuando la ocasión se presentase; la cual no tardó en suceder». 
nedio ne manda altruì. E così dicendo e avendo del tutto mutato proposito da quello per che andato v'era, fattosi più presso alla giovane, pianamente la cominciò a confortare e a pregarla che non piagnesse; e d'una parola in altra procedendo, ad aprirle il suo desidero pervenne.

(francés) «Pour quoi me priverais-je d'un bien qui s'offre à moi? Je souffre assez de privations, sans y ajouter encore celle-là! Ma foi, cette fille est tout à fait charmante! Pourquoi n'essayerais-je point de la conduir à mes fins? Qui le saura? Qui pourra jamais en être instruit? Péché secret es à demi pardonné. Profitons donc d'une fortune qui ne se représentera peut-être jamais, et ne dédaignons point un plaisir que le ciel nous envoie.» Dans cet esprit, il s'approche de la belle affligée; et, prenant un tuot autre air que celui qu'il avait en entrant, il cherche à la tranquilliser, en la priant avec douceur de ne point se chagriner. "Cessez vos pleurs, mon enfant; je comprends que vous avez été séduite: ainsi ne craignez point que je vous fasse aucun tort; j'aimerais mieux m'en faire à moi-même» Il la complimenta ensuite sur sa taille, sur sa figure, sur ses beaux yeux; et il s'exprima de manière et d'un ton à lui laisser entrevoir sa passion.

1876 «Por qué privarme de un bien que se me viene a las manos? Bastantes privaciones sufro, para que tenga que añadir esta. En verdad, esta jóven es deliciosa. ¿Por qué no tratar de inducirla a los fines que me propongo? ¿Quién lo sabrá? ¿Acaso puede divulgarse este negocio? Pecado secreto está mitad perdonado. Aprovehémonos, pues, de una fortuna que tal vez no volverá a presentármese nunca mas, y no despreciemos un placer que el cielo nos envía.» Animado de tales propósitos se acerca a la hermosa afligida, y tomando un aire muy distinto del que tenía al penetrar en la celda, trata de tranquilizarla, suplicándola con dulzura, que no se desazone. "Cese vuestro llanto, hija mía; comprendo que habeis sido seducida; por lo tanto, no temais que os haga ningún daño; preferiria, al contrario, hacérmelo a mí mismo». Enseguida ensalza su talle, su rostro, sus lindos ojos, y se expresa de tal suerte y con un tono que deja entrever su pasión.

$1884 \mathrm{~b} \quad[\ldots]$

1920? Habiendo fijado en ella los ojos el señor abad, y viéndola hermosa y fresca, aun cuando ya era viejo, no por eso se sintió menos impresionado de lo que se sintiera su joven monje, y pensó en proporcionarse un rato de placer cuando tan a mano se le venía la ocasión y nadie había de saberlo.

1924 Era el abad hombre de corazón muy blando, y pronto sintió compasión por aquella infeliz: primero le habló con severidad, des- 
pués cortésmente, luego con afabilidad, y por último con ternura. Parecíale la muchacha algo así como una imagen, y como de ninguna santa había estado tan cerca, se arrodilló a sus plantas, rezongando palabras incoherentes que tenían algo de ruego y apasionada oración.

-Tú habrás venido al convento, sin duda alguna, a confirmarte, ¿no es así, muchacha? Pues bien, procuraré complacerte.

$Y$ al decir esto le dio un suave toquecito en la sonrosada mejilla, tal como lo requiere el sacramento, y para mayor seguridad lo repitió hasta tres veces.

Después le enseñó a persignarse, y llevándole la mano, le hizo la señal de la cruz en la frente, en la boca y en los pechos, en todas las partes, en fin, que es de ritual. En seguida, se sentó a su lado y principió a confesarla: ella, muy reverentemente, le besó la mano, y él supo corresponder con cortesía y quizá con exceso a tales demostraciones.

La traducción francesa amplifica exageradamente el original, suavizándolo al mismo tiempo; [1876] lo sigue muy de cerca, mientras que [1920] opta por hacer un resumen edulcorado de la situación. Por contra, [1884b] censura todo el pasaje, deformando enteramente la novella (en su lugar encontramos varias líneas de puntos, signo de censura, no sabemos si editorial o del propio traductor). Hemos añadido la traducción de [1924] como muestra de una modificación delirante que inventa incluso detalles como el de la comunión, si bien la metáfora podría funcionar como equívoco erótico.

En conjunto, la lengua empleada por los traductores resulta pobre, a menudo pedante y recargada cuando se intenta dar un toque de antigüedad, o banal e incluso vulgar cuando se moderniza. Ninguna de las traducciones, independientemente del texto fuente utilizado, revela un esfuerzo de trasposición estilística digno de relieve. Interesa la anécdota, no la forma de narrarla.

\section{El paratexto ${ }^{27}$}

En dos de las traducciones íntegras ([1904] y [1928]) sorprende, en una empresa de tal magnitud, la ausencia de cualquier tipo de introducción, comentario o nota encaminados a orientar al lector. Otras, en cambio, incluyen elementos paratextuales, que comentaremos brevemente.

27. El Catálogo del Proyecto Boscán, además de los datos bibliográficos y de otro tipo sobre las traducciones, ofrece en numerosas ocasiones transcripciones de las propias traducciones o de elementos del paratexto, además de reproducciones de imágenes de portadas, textos, ilustraciones, etc. Remitimos, pues, a dicho Catálogo para completar la información que se comente en este apartado. 
La de [1818] está precedida por un interesante prólogo del traductor en el que manifiesta sus preferencias literarias, probablemente coincidentes con las del público culto de la época. Para Torres, Boccaccio es un autor al que reconoce el mérito de tener un "estilo elegante y puro", pero no deja de reconocer que «sus Cuentos son pesadísimos, la acción a veces extravagante, a veces sumamente complicada, y a veces inverosímil, y las digresiones e intrigas no suelen ser siempre muy felices» (p. VIII). Sus preferencias van hacia Lafontaine (que no se libra de críticas, pues hubiera podido recargar «menos sus exordios y peroraciones»), aunque a todos antepone a Ariosto y muy especialmente a Casti. De Boccaccio aprecia, por tanto, los temas, y de hecho afirma haberse limitado como traductor a "tomar su asunto y sus principales ideas, y componerlo después todo a mi modo».

Solo dos traducciones incluyen alguna orientación biobibliográfica sobre Boccaccio. La de [1876], traduce la Nota introductoria de alguna de las ediciones francesas de Garnier hermanos: se trata de una simple semblanza de tipo hagiográfico, en la que se ensalza la inclinación a las letras del autor. Muy diferente es la de Eduardo Barriobero [1932], que traza un desenfadado, chocarrero y disparatado retrato de Boccaccio, personalísimo, coronado con la siguiente conclusión: «La obra de Boccaccio es copiosa y trascendental. Acaso de ella lo menos estimable son los cuentos licenciosos del Decameron, que le han traído a la posteridad». Al referirse a la crítica anticlerical — lo que realmente le interesa de esta obra - dice: «No tienen razón de quejarse los curas, los frailes y las monjas que en el Decameron ven retratados a sus semejantes. Eran así, y el autor no podía pintarlos de otro modo. [...] Aún han de estarle agradecidos de que los haya descrito en una prosa magnífica, ejemplar, opulenta de imágenes y de giros sutiles, que ha servido de pauta segura a muchas plumas francesas y españolas que por entonces comenzaban a soltar los andadores latinos».

Señalaremos por último la "Advertencia del restaurador del Boccacio" de [1925], en la que de modo disparatado (citando incluso la autoridad de Ortega y Gasset) el anónimo traductor justifica con tópicos argumentos su torpe operación de "puesta al día» de la novella III 3: «[...] sus textos, su prosa, no están acordes con el ritmo del habla actual [...] A tales obras es menester, como a los cuadros que el tiempo ha hecho borrosos, restaurarlas para que susciten todavía la admiración del común de las gentes. [...] Así yo, sirviéndome de la noveleta de Boccacio como de un simple esquema, he trazado con entera libertad mi historia de El jardinero mudo, las ocho hermanas y la madre, y aquí os la presento.»

Más profusa es la iconografía que acompaña a estas traducciones. Muchas de ellas incluyen grabados o dibujos en el interior o en sus portadas, que denotan la visión pintoresca que de la obra se tenía en esa época. Las primeras imágenes son las de [1882], tomadas, como no podía ser de otro modo, de la traducción francesa publicada por Garnier hermanos, con gran profusión de grabados obra de conocidos artistas franceses, citados en lugar bien visible en la portada como gancho publicitario (Johannot, Nanteuil, Staal, Girardet, etc.). Son de inspiración post-romántica, melodramática, acentúan el carácter dramáti- 
co (diríamos casi folletinesco) de la acción y las pasiones de los personajes; en el aspecto erótico no son en absoluto explícitos. Muy similares son las imágenes de la traducción de Aranda [1888a], que reproducen el ideal romántico de la Edad Media. Algunas de ellas han inspirado sin duda las de Cabanellas para [1904], pues son casi idénticas.

Tres de las traducciones del siglo XX tienen en sus portadas ilustraciones de carácter muy diferente: [1920], en la portada que agrupa los 25 cuentos vendidos por entregas, presenta una imagen en color referente a la novella VII 2, en la que se ve a Peronella y a su marido, así como el barril en el que está escondido el amante de aquella. La de [1924] es también en color y resulta muy explícita acerca de la idea global que se intenta dar del libro: un fauno con mirada lasciva ocupa toda la portada. La de [1933], más sobria, reproduce en cambio el busto de un elegante caballero renacentista, apuntando a la italianidad y antigüedad de la obra.

Un caso aparte es [1925], que convierte la novella de Masetto en un relato pornográfico completamente ajeno a Boccaccio, acompanándolo de varias ilustraciones en blanco y negro, todas de contenido erótico bastante explícito.

\section{Conclusión}

Los datos expuestos hasta aquí no permiten realizar un balance demasiado halagüeño. En el período comprendido entre 1818 y 1933 Boccaccio llegó al público español casi siempre bajo una óptica deformada, por uno de estos motivos:

- eliminación total o parcial del marco narrativo, reduciendo así la obra a una suma de cuentos, cuyo orden se altera también a discreción;

- selección arbritraria de ciertas novelle en detrimento de otras, que en ningún caso se intenta justificar. Cuando el criterio es homogéneo, prevalece la reducción de Boccaccio a un autor jocoso, lúbrico y anticlerical;

- deformación drástica del texto original, bien para adaptarlo a otros géneros (el cuento en verso, el libreto de zarzuela), bien por una arbitraria manipulación del traductor ([1925]);

- traducción indirecta a partir de otra francesa, ya de por sí deformante especialmente en lo que atañe a simplificación sintáctica.

En todos los casos es evidente que la mayoría de los traductores ofrecen versiones en un español mediocre o bien demasiado alejado del original, a veces, incluso, muy personal del traductor, que no tiene empacho en ponerse en primer plano, por delante de Boccaccio (Barriobero [1932], Olmedilla [1925]).

Así pues, la mayoría de las traducciones estudiadas no ha hecho sino perpetuar el estereotipo de un Boccaccio libertino que no favoreció su incorporación al canon de los clásicos. Ésta se produjo sólo a partir de los años Sesenta del siglo XX con un retraso considerable respecto a otros autores italianos. 


\section{Anexo 28}

Traducciones y adaptaciones del Decameron en España en el período 1818$1933^{29}$

\section{[1818]}

Cuentos en verso castellano, por el licenciado Don Tomás Hermenegildo de las Torres. Perpiñán: Luis Craset y compañía, 1818, p. 6-13, 21-28. 35-40, 67-75. XII, 83 p. $14 \mathrm{~cm}$. [VII 3, VIII 2, VII 6, VII 7].

- Madrid: s.n., 1820.

- Valencia: s.n., 1820 ca. (Imprenta de la viuda de Garriga).

- Madrid: s.n., 1821.

- Valencia: s.n., 1821 (Imprenta de la viuda de Garriga).

- Zaragoza: Impr. Real, 1828.

28. Se da entre corchetes el nombre del traductor si no aparece entre los datos bibliográficos. Entre otros corchetes se indican las novelle traducidas, en el orden en el que aparecen.

29. Se excluyen las siguientes reediciones de traducciones antiguas:

La marchesana de Monferrato, novella di mess. Giovanni Boccaccio. Voltata in lingua spagnuola con note e saggio bibliografico di alcune edizioni del Decamerone. Venecia: Tip. Giambattista Merlo, s.a. [I, 5].

Johan Boccaci, Decameron, traducció catalana publicada segon l'unic manuscrit conegut (1429) per J. Massó Torrents. New York: The Hispanic Society of America, 1910 [Texto completo]:

- Joan Boccaccio, Decameró: versió catalana de 1429. Introducció de Carles Riba. Barcelona: Barcino (Els Nostres clàssics. Col-lecció A; 8,17), 1926-1928, 2 vols. [Jornadas I y II].

- La Història de Valter e Griselda, arromançada per Bernat Metge. Seguida de les de La Filla del rey d'Hungria, Frondino e Brisona y Paris e Viana: textes originals autèntichs publicats en vista dels manuscrits y edicions primitives [por Ramon Miquel i Planas]. Barcelona, 1910 [X 10, de la traducción latina de Petrarca].

El Manual del librero hispanoaméricano de Palau cita otras dos traducciones de las que no hemos encontrado ningún rastro:

- Cuentos. Segunda serie. Trads. por Emilio Ma. Martínez. B[arcelona], Gassó hermanos, $8^{\circ}, 288$ p. [31149]

- Cuatro cuentos. M[adrid], Compañia Ibero-Americana de Publicaciones (1931) 16º, 112 p. (1 pta.) [31152] lizar:

El mismo Palau menciona otra traducción catalana, que tampoco hemos podido loca-

— Contes de Boccaccio. "Papitu». (Sin lugar, pero B[arcelona], hacia 1912), 8, 170 p. grabs. Selección y arreglo publicado por el semanario humorístico «Papitu» [31158] 


\section{[1849]}

Jardin de Venus adornado con flores de diversos matices, ó sean cuentos escogidos de Grecourt, Boccaccio, Lafontaine y otro, con algunos originales. Puestos en verso castellano por el R.p. Fray C. Alegre. Bruselas: Coster et cia., 1849, p. 217243. 312, [4] p. $13 \mathrm{~cm}$. [VII 9] ${ }^{30}$

\section{[1865]}

Obras clásicas españolas y estrangeras. Madrid: Imprenta de Manuel B. de Quirós, 1865, p. 9-16. 64 p. 15 cm. [traducción anónima] [VII 7]

\section{[1875]}

I parlari italiani in Certaldo alla festa del V centenario di messer Giovanni Boccacci. Omaggio di Giovanni Papanti. Livorno: Francesco Vigo, 1875, p. 712714.736 p. [trad. al catalán literario y al catalán dialectal de Barcelona de Manuel Milà i Fontanals] [I 9]

\section{[1876]}

Cuentos de Boccaccio. Barcelona: Administración de la Biblioteca de la Risa, Librería La Anticuaria, $1876 .^{31} 4$ t. en 1 v. (146, [1]; 139 [1]; 128, [1]; 175, [1] p. ) $19 \mathrm{~cm}$. [Traductor: sin determinar con seguridad] ${ }^{32}$ [Traducción de todas las novelle. Del marco sólo el Proemio y la Conclusión]

\section{[1882]}

Cuentos de Boccaccio. Traducidos por Leopoldo García-Ramón. Ilustraciones de Johannot, Nanteuil, Staal, Girardet, etc. París: Librería Española de Garnier Hermanos, 1882. 2 v. (319, 123 p. ) [Traducción de todas las novelle. Del marco sólo el Proemio y la Conclusión]

— París: Librería de Garnier Hermanos, 1888.

— París: Librería de Garnier Hermanos, 1890.

30. Es muy probable que se trate de tres casos en los que el celo de la censura franquista consiguió eliminar completamente su rastro (casi lo consiguió en otro: [1932]).

Es la única novella cuya presencia he podido identificar, pero no es descartable que otras estén presentes en este libro.

31. Existen varias tiradas con paginaciones diferentes en el mismo año. Para más detalles consúltese el registro n. 947 del Catálogo del Proyecto Boscán.

32. La traducción es anónima, aunque lo más probable, siguiendo a Palau, es que el traductor haya sido Mariano Blanch (único traductor de la editorial para obras literarias), quien tradujo numerosas obras, todas del francés. Más inverosímil resulta la hipótesis de la autoría de Leopoldo García-Ramón, que figura como traductor de una versión idéntica, aunque publicada en París seis años más tarde (1882). 


\section{$[1884 a]$}

Un cuento de Boccaccio: opereta cómica en un acto y en prosa. Libro original de Manuel Cuartero, música del maestro Rafael Taboada. Madrid: s.n., 1884 (Establecimiento tipográfico de M. p. Montoya y Compañía). 21 p. $19 \mathrm{~cm}$. [VII 7]

\section{$[1884 \mathrm{~b}]$}

Un cuento de Boccacio: castigo burlado. En: La momia, por Catulle Mendès; Frritt-Flace, por Julio Verne; Relojería, por Armand Silvestre; Un artículo, por R. Torromé; El cura pobre, por J. Francos Rodríguez; Un cuento de Boccacio, por A. García Vao. Madrid: Biblioteca Reformista, s.a. [1984?], (Biblioteca Reformista; 3), p. 87-93. 93 p. 16 cm. [Traducción de Antonio R. García Vao]. [I 4]

\section{[1888a]}

Cuentos escogidos de Giovanni Boccaccio. Traducidos directamente del italiano por Manuel Aranda y Sanjuan. Barcelona: Casa Editorial de la Viuda de Juan Trilla, 1888. 198 p. $19 \mathrm{~cm}$. [V 1, V 3, II 5, X 10, VIII 3, VIII 5, X 6, III 2, III 3, III 9, V 2, IV 5, V 9, VIII 9, VIII 10, VIII 6, VIII 7]

\section{[1888b]}

Satanás en la abadía (otro cuento de Boccacio). Opereta cómica en un acto y en prosa. Letra de Manuel Cuartero, música original del maestro Rafael Taboada. Madrid: s.n., 1888 (Imp. de M.p. Montoya). 22 p. 19 cm. [I 4 o bien IX 2]

\section{[1898]}

Dos cuentos de Boccaccio. Traducidos directamente de El Decameron. Barcelona: Maucci, 1898. 29 p. 16 cm. [Sólo III 1 y III 10] ${ }^{33}$

\section{[1904]}

Los cien cuentos de Boccaccio, cotejados con los mejores textos italianos y fielmente traducidos al castellano por Luis Obiols. Barcelona: Maucci, 1904, 4 v. (252, 234, 252, 304 p. ). 19 cm. [Traducción íntegra]

- Buenos Aires: El Ateneo, 1953

- Barcelona: Maucci, D.L. 1963, 1964

33. El punto de partida puede ser el texto de Garnier Hermanos o bien el de [1876], que son idénticos. 
- Barcelona: Credsa, [1965], [1968], [1972]

- Bilbao: Moretón, [1973], 1980

- Madrid: Club Internacional del Libro, D.L. 1978

- Barcelona: Castell y Moretón, D.L. 1981

- [Bilbao: I.B.C.], [1982]

\section{[1906]}

La Guedeja rubia. Opereta en un acto. Letra de Fiacro Yrayzoz, música de V. Lleó, decorado de Luis Muriel. Madrid: Fuentes y Asenjo, 1906. 43 p. 33 $\mathrm{cm}$. [III 2]

— Madrid: s.n., 1919

\section{[1909]}

¡Ábreme la puerta! Opereta en un acto y tres cuadros, inspirada en un cuento de Boccacio. Letra de Fiacro Yráyzoz, música del maestro Amadeo Vives, decorado de Amalio Fernández. Madrid: Sociedad de Autores Españoles, 1909. 33 p. $21 \mathrm{~cm}$. [VII 4]

\section{[1911]}

El tonto de las monjitas. Cuento en acción inspirado en uno de Bocaccio. Letra y música del maestro Emilio Alonso Valdrés. Madrid: s.n., 1911 (Imprenta de la Ciudad Lineal). 18 p. 19 cm. [III 1]

\section{[1920]}

Cien cuentos de Boccacio. Adaptados al castellano y arreglados por Luis Larrañaga. Madrid: s.n., s.a. [1920 ca.] (Tip. La Itálica). 192 p. 17 cm. [IV 9, VII 10, IV 5, I 4, VI 8, IV 10, IV 8, VI 6, IV 7, I 2, VIII 1, VIII 8, IX 6, VIII 2, IX 7, IX 10, VIII 4, I 6, X 1, II 2, II 10, I 3, II 9, X 2, IX 5$]^{34}$

\section{[1921]}

El jardín del pecado: antología erótica. Selección, prólogo y notas de Andrés Guilmain. Madrid: Rafael Caro Raggio, s.a. [1921]. v. III, p. 93-130. 159, [5] p. $19 \mathrm{~cm}$. [III 1, III 2, III 3]

34. Sólo se ha podido localizar el segundo volumen, que incluye las novelle indicadas más arriba. No se ha podido encontrar ningún ejemplar del primero, ni del tercero o cuarto, que es de suponer que completarían la colección de las cien novelle anunciada en el título. 


\section{[1924]}

Los cuentos más alegres y mejores del Decamerón. Madrid: Editorial Marineda, 1924. 203, [20] p. $20 \mathrm{~cm}$. [I 4, VII 7, III 1, V 10, X 4, II 10, IX 2, VII 2, VIII 2, I 10, IX 3, III 2, II 2, I 6, VIII 8, VII 6]

\section{[1925]}

El jardinero mudo, las ocho hermanas y la madre. Un cuento de Boccacio vestido y desnudado en lengua española, por su tocayo Juan G. Olmedilla. Ilustraciones de Zala. Madrid: Flérida, s.a. (La novella exquisita; año 1, n. 9). 58 p. $18 \mathrm{~cm}$. [III 1]

\section{[1928]}

Decamerón. Versión española de Germán Gómez de la Mata. Valencia: Prometeo, s.a., 4 v. $(236 ; 226 ; 261 ; 235$ p. ). 19 cm. [Traducción íntegra]

\section{[1932]}

Frailes, curas y monjas de Boccaccio: antología de cuentos eróticos. Ordenacion y prologo de E[duardo] Barriobero y Herrán. Madrid: Mundo Latino, 1932. ${ }^{35}$ 201 p. 17 cm. [III 1, I 2, I 4, III3, III 4, III 8, III 10, IV 2, IX 10, X 2, IX 2, VIII 2, VII 7, VI 10, VII 5]

- Madrid: Casset, D.L., 1992.

- Madrid: Ágata, 1995.

\section{[1933]}

Los mejores cuentos (novella picaresca). En: Revista Literaria Novelle y Cuentos, n. 230 (28 de mayo de 1933). [II 5, II 3, II 7, III 2, III 3, III 7, IV 1, I 3, IV 10, IV 8, III 6, IV 4] 